\title{
DAS OPERAÇÕES DIGITAIS À AUTO-ORGANIZAÇÃO: a cognição computante
}

\author{
Heloisa Pedroso de Moraes Feltes ${ }^{\star}$
}

\begin{abstract}
Resumo: O artigo caracteriza extensamente o paradigma computacional da merle a partir da transcendentalidade do compulador como dispositivo tecnico que formece uma matriz estruturante a partir da qual concebem-se os seres vivos, us processos oogritivos e o viniverso social. Desde esse contexto de uma cultura fijosoflico-cientifica impregnada pelia matriz compulacionat, apresentam-se as coordenadas conceituais de una in!re as muifas propostas alterthativas a esse paradigma: a Teoria de Santiago, na perspectiva dos sistaruas oomplexos auto-organizadores.
\end{abstract}

Palavras-chave: teoria computacionai de mente, tearia de Santiago

Abstract: This paper chatecterizes exterisively the computatonal paratigm of the mind from the point of view of computer transcendentallity as a techmical devke whlch provides a structuring matrix from which we conceive living beings, cogritive processes, and the social uriverse. Based on this context of a philosoghical and scientific culture impregnated by the computatlenal matrix, we present the conceptuat conrdinates of one among many other alles native proposats to this paradigm: Santiago's theory, aceording to self-organizing complex systems.

Key words: Computational theory of mind, Santiago's theory

A Ciència Cognitlva constitui um dominio cuja formação é o resultado de estudos oriundos de diferentes areas de conhecimento. Sua caracteristica essencial é a interdisciplinaridade e, contemporaneamente, a transdisciplinaridade: Os cientistas da cogniçăo advêm de áreas, tais como: Inteligència Artificial, Psicologia, Lingüistica, Antropologia, Filosofia da Mente (e da Linguagem), Neurobiologia, para citar algumas, que se ocupam, sob alguma perspectiva epistemo-metodologica, da natureza, da estrutura e dos processos da cognição humana.

Desde a constituiçào deste dominio $0^{2}$ ao longo de aproximadamente trếs decadas preponderou, paradigmaticamente, a hipótese de que os processos mentais humanos poderiam se comparados ou, numa versão mais forte da hipótese, assimilados a operaçōes de una máquina de Turing. Tem-se al o fundamento para a teoria de mente computacional desenvolvida a partir "da concepçăo do cérebro como um mecanismo processador de informaçốs, análogo ao computadớ" (uackendoff, 1987, p. 15).

Pretende-se caracterizar aqui o paradigma computacional da mente construido, conforme Lèvy (1987, 1993), em função da transcendentalidade do computador como dispositivo técnico que fornece uma matriz estruturante a partir da qual concebem-se os seres vivos, os processos cognitivos $\theta 0$ universo social. Desde esse contexto - de uma cultura filosófico-cientifica impregnada pela matriz computacional -, apresentam-se as coordenadas conceituais de uma entre as muitas propostas alternativas a esse paradigma: a Feoria de Santiago, na perspectiva dos sistemas complexos auto-organizadores.

A analogia com o computador implica na hipotese, que fundamenta a abordagem funcionalista ${ }^{3}$, de que se pode investigar a informaçäo processada pela mente (entendida como software) independentemente do se tratar da implementaçăo neurofisiológica pelo cérebro (entendido como hardware). O funcionalismo adere a um programa reducionista que defende a idéia de que os estados mentais säo supervenientes ${ }^{4}$ a estados neưonais, que săo, am última instância, fenômenos neurofisiológicos. ${ }^{5}$

Nessa direçäo, Pylyshyn (1986) afirma:

a que o cerepro esté fazendo ex exatamente o que os computadores fazem quandio eles computam funçóes numericas; a saber, seu compontamento é causado por propriedades fisicamente instanciadas de classes de substratos que corresponden a codigos simboticos (p. 39).

Menteicérebro constituem, assim, um processador de informaçōes cuja base é uma linguagem digital. Esta idéa passou a ser chamada de metáfora do computador.

\footnotetext{
- Professora, doutora em Lingüistica Aplicada (PUCFS), professora dos Departamentos de Letra e Comunicaçăo da Universidade de Caxjas do Sul
} 
O que é essa linguagem dlgital? Gregory (1987) define-a da seguinte maneira:

Digital significa essencialmente representar estados ou exectutar procedimentos matemáticos ou lógicos em passos que correspondem a operaçōes simbólicas de urr calculo.

Um computador digital opera em passos que representam passos da lógica ou que computam por mein de urtr código formall. Porque os símbolos da lógica ou do calculo aritmético săo discretamente diferentes uns dos outros, os computadores digitais requerem circuitos que tem estados diferentes uns dos outros, os computadores digitais requerem circuitos que tem estados discretos, que podem ser splépionados err grande velocidade (p. 192) ${ }^{6}$.

A cognição é concebida, nessa fase das ciências cognitivas, como um programa que roda numa máquina (cérebro). E pela abordagem funcionalista, como se vit, o programa é algo abstrato que pode rodar em tipos diferentes de harowares. Como diz McGuinn (1996), nessa visāo, "pensar é o cérebro rodando seus programas de computador". Um programa seria um algoritmo para manipulação simbólica, ou seja, "um conjunto de instruçōes para manipular simbolos, concebidos como objetos sintáticos" (p. 111). Esse modelo é conhecido como arquitetura cognitiva clássica da cogniçāo. Enfirn, a cognição é, aqui, processamento de informaçāo através de um sistema formal". Nessa višäo clássica, tepresentacionalista, as representaçóes mentais (ou os simbolos mentais) \$äo sobre o mundo, ou seja, de alguma maneira carregam informaçöes sobre o mundo: que é o que define a intencionalidade. Ela é aboutress, no sentido de que "algumas coisas sâo sobre outras coisas". A mente seria, assim, constituida de um sistema de representaçós mentais, o qußl exibe intencionalidade intrínseca - também chamada de primária ou não-derivada -. Expressōes ou construçōes das línguas públicas tèm intencionalidade secundária oџ derivada ${ }^{5}$

Imbricada á concepção de mente como processador simbólico está a hipótese de uma linguagem do pensamento. A idéia de sustentaçăo jara a linguagem do pensamento é a suposiçăo de que o comportamento e fesultado de computaçăo, e esta, por sua vez, pressupōe um medium, um sistema de representaçóes ou linguagem do pensamento. As rotinas computacionais que constituem o repertório cognitivo dos organismos são, portanto, definidas apenas por fórmulas de uma linguagem interna. Ou seja:

a representzçăo pressupäe um medium de representaçăo, e nảo há sjmbolizaço sem símbolos. Em particular, năo há representaçăo interna sem uma linguagem interna (FODOR, 1976, $\mathrm{p}$. 55).

Para Fodor, essa linguagem interna năo è uma lingua natural, mas compartilha varias propriedades com as linguas naturais. Uma delas é a produtividade, Assim como os falantes de uma língua têm uma competencia que |hes perrite produzir e entender uma infinidade de novas sentenças, sem treinamento anterior especifico, um sistema simbólico representacional intemo habilía o organismo a responder a novas estimulaçōes, ou seja, habilita-o "a calcular as opçōes comportamentais apropriadas para um tjpo de situação em que ele nunce se encontrou antes:" (1976, p. 31-2). A linguagem do pensamento não é aprendida, mas é conhecida. Assim sendo, ela é inata, estando disponivel como sendo o véiculo de processos cognitivos.

Outra caracteristica é a de que as fórmulas do sisferna representacionąl exibem propriedades semạnticas relativas à sua capacidade de representar a realidade e estados de coisas possiveis. Essas propriedades envolvem, portanto, verdade e referência. Nessa abordagem, quando se aprende o que um predicado em língua natural significa, sua extensáo é representada na linguagem do pensamento. Fodor (1976) descreve esse procedimento de modo idealizado:

(i) os sistemas computacionais têm no minimo duas linguagens diferentes: (a) uma linguagem de input loutput atraves da qual è possivel a comunicaçäo com o ambiente e (b) uma linguagem da máqulna atraves da qual sáo executadas as computaçöes;

(ii) há compiladores que fazem a nediaçăo entre as duas linguagens, especificando bicondicionais, em cujo lado esquerdo está uma fómula no código de input loutput e em cujo lado direito está uma fómula da linguagem da máquina, os quais säo representaçōes de condiçōes-de-verdade para fórmulas na linguagern de inputí output:

(iij) a habilidade da máquina para usar esta linguagem depende da disponibilidade dessas definiçōes;

(W)embora a maquina deva ter um compilador para usar a linguagem de input/output, ela não tem um compilador para a linguagem da máquina, pois a máquina é construída para usar essa linguagem;

(v) assim, a linguagem da máquina difere da linguagem de inputioutput porque suas fórmulas corespondem diretamente aos estados fisicos e operaçōes da máquina computacionalmente relevantes, de modo que a física da máquina garante que as seqüuencias de estados e operaçōes respeitem as restriçöes semànticas sobre as fórmulas em seu código interno: 
(vi)a fortiori, a definição de verdade para a linguagem da máquina è dada pelos principios de engenharia que garantem esta correspondéncia.

Desse modo, segundo Fodor:

A propriedade crítica da linguagem-da-máquina de computadores é que suas formulas podem ser correlacionadas diretamente com os estados fisicos computacionalmente relevantes da máquina, de ta! forsta que as operaçoses que a maquina realiza respeitem as restriços semănticas sobre formulas no código da máquina. Tokens de estados da máquina sao, messe sentido, interpretaveis como tokens de fórmulas. Tal correspondência pode tambén ser efetuada entre estados flsicos da máquina e fómullas do código de inputtoutpuț, mas apenas se traduzidas primeiro nume linguagem da maquina (1976, p. $67)$.

Como corolàrio desse conjunto de comprometimentos, toda essa geraçāo em Ciēncia Cognitiva assume o solipsismo ${ }^{10}$. Considerando a tese de que estados e processos mentais são computacionais, filósofos como Fodor fazem o seguinte raciocínio:

- Os processos computacionais sāo simbólicos, porque são definidos sobre representaçōes.

- Os processos computacjonais são formais, porque se aplicam a representaçōes, a grosso modo, em vista da sintaxe das representaçóes ${ }^{11}$.

As relaçōes semànticas teriam alguma relação homomófica com as relaçōes sintáticas, de modo que as operaçóes computacionais exploram paralelismos entre a sintaxe de um símbolo e a semántica desse símbolo - o que Fodor caracteriza como "a receita para a racionalidade mecanizante" (1987, p. 23).

Decortente da estruturaçäo simbólica ern nivel sintático, a arquitetura clássica exibe produtividade, isto é, a propriedade de os sistemas simbólicos poderem expressar um conjunto infinito de proposiçóes; ou, em outras palavras, a produtividade refere-se à capacidade de se gerar um novo pensamento além daqueles já presentes num dado corpus. Fodor e Pylyshyn (1988) sustentam que sistemas simbólicos dảo conta de produtividade e siștematicidade. porque fazem uso de uma sintaxe composicional das representaçoes internas e porque o significado das estruturas compostas são construidos a partir dos componentes de acordo com aquelas regras sintáticas.

Mas hà outros aspectos a serem considerados neste modelo de funcionamento mental. Um deles é sua articulação com alguma versão da hipótese de modularidade da mente. A proposta de mente modular de Jerry A. Fodor (1983) ${ }^{1 \hat{2}}$, a mais referida nas últimas decadas, basela-se numa taxonomia funcional tricotỏmica dos processos psicologicos, distinguindo: transdutores, sistemas modulares de input, e sistemas ou processadores centrais. Sumaliamente, de acordo com Fodor (1990), um modulo pode ser definido como um sistema computacional encepsulado cujo acesso à informaçăo de background é restringido por traços gerais da arquitetura cognitiva, de modo que suas operaçöes $\$ 0$ têm acesso a informaçăo de seu banco de dados. Os sistenas modulares săo classificados como sistemas de input, porque funcionam no sentido de jogar informaçăo nos processadores centrais - estes tendo de integrar as informaçóes advindas dos diferentes módulos. Desse ponto de vista, eles cabe representar o mundo de modo a que tais representaçóes sirvam ao pensamento. Já os transdutores nada mais săo do que sistemas de base neurofisiotógica responsáveis pela traduça da estimulação proximal em sinais neurais, promovendo a alteração do formato da informação (não de seu conteúdo). Os sistemas de input, portanto. medeiam os outputs dos transdutores e os mecanismos centrais.

Sistemas de inputs e sistemas centrais săo computacionais no sentido de que realizam operações de inferancia. Entre as propriedades dos sistemas de input levantadas por Fodor (1983) destacam-se as seguintes:

- Os modulos tem dominio especifico, porque realizam tarefas especiajizadas.

- Eles têrn acesso central limitado às representaçōes mentais que computam, porque não seria possivel ter acesso a todos ds niveis de representação dos módulos, mas apenas às representaçōes que săo as conseqüências finais do processamento de input e que estäo disponiveis para os processos centrais.

- Os módulos săo informacionatmente encapsulados porque as computaçōes dos sistemas de input näo tēm acesso ilimitado a expectativas ou crenças, havendo efeitos intramodulares que devern ser distinguidos da penetrabilidade cognitiva. Os processos perceptuais são insens weis ao conhecimento de beckground do percebedor, sendo sincronicamente impenetráveis (Fodor, 1990). 
Já os sistemas de processamento central realizam computaçóes que săo sensiweis ao sistema global de crenças. Não há limites sobre o acesso informacional, e as informaçōes sảo interconectadas em processos inferenciais nåo-demonstrạtivos com viștas à tixação de crenças e a resoluçăo de problemas.

Para o autor, o fato de os sisternas centrais serem sensiveis à estrutura geral do sistema de crenças do organismo caracteriza-os como globais ou isotrópicos. Nos sistemas isotrópicos qualquer subsistema pode querer "falar" com outro a qualquer momento, e isso corresponde a uma neuroanatomia relativamente difusa, em que as conexōes podem ser alteradas a qualquer momento de acordo com as interaçes estabelecidas (o que é conhecido como equipotencialidade da estrutura neural).

Fodor (1990) resume as caracter(sticas dos processadores centrais em (a) nāo-encapsulados, (b) criativos, (c) holistas e (d) analógicos.

Jackendoff (1983, 1987, 1992) também tem afirmado que a inteligência origina-se da presença: no cérebro, de vários órgăos mentais especializados, "cada um dos quais tem sua própria linguagem particular" (1992, p. 19), mas diferentemente de Fodor, toma o sistema central como também modularizado. Para ale, a Estrutura Conceptual (EC) e parte de um conjunto de módulos centrais; a EC, a cogniçáo espacial a a representaçäo do corpo. A EC, o módulo mais conectado à linguagern, codifica individuos e categorias e suas combinaçöes em estados e eventos token e type, em domínios concretos e abstratos. A cogniçăo espacial recebe input da višăo, tato e audiçäo, e as representaçōes espaciais por ela geradas servem como input para a formulaçăo da açăo no mundo. A EC e a cogniçăo espacial operam juntas para o entendimento do mundo físico.

Propostas muito difundidas de estrutura e funcionamento mental como a de Gardner (1983) baseiamse nessa concepção da cognição como processamento de informação. Embora Gardner faça críticas à psicologia do processamento de informaçōes, ele concorda com alguns de seus pontos básicos. Diz ele que eda introduziı avanços importantes:

\begin{abstract}
Agora temos a disposiçâ uma concepçăo muito mais dinámica do que ocorre no decorrer da resoluçăo de problemas: se inclui um quadro de "entrada" de informaçöes ou mecanismos de acesso; as formas de retençăo imediata e de curto prazo se aproximam da informaçáo até que possam ser codificadas na memória; várias aperaçōes de gravaça e transformaçăa que podem ser impostas sobre a Informaçăo recém-adquirida (p. 18, da ediç̧o brasileira; grifos da autora).
\end{abstract}

Gardner simpatiza com a hipótese da modularidade da mente: a de que há mecanismos de processamento de informaçōes de finalidade especifica (mecanismos computacionais): molares e moleculares, específicos de uma espécie ou năo. Sua adesăo a uma versão de modularidade, fundada na idéia de computaçāo, passa, entretanto, pelo questionamento de caracteristicas estruturais e de processamento do sistema central de informaçóes e sobre a natureza dos módulos e suas interaçoes:

Conforme vejo as evidencias, tanto os achados de psicologos sobre o poder de diferentes sistemas simbólicos: quanto os achados de neurocientistas sobre a organizaçāo do sistema nervoso humano apóiant o mesmo quadro da mente humana: a mente consiste em alguns mecanismos computacionais bem especificos e bastante independentes ( $\mathrm{p}$. $43 \mathrm{da}$ ediç̧o brasileira; grifos da autora).

O autor afirma que evidencias biológicas apontam para duas conclusões: (a) há uma grande plasticidade no crescimento humano, especialmente durante os meses iniciais da vida, modulada por restriçöes genéticas; (b) os seres humanos sāo predispostos a desempenhar algumas operacónes intelectuais especificas ou desenvolver determinados padrỏes de comportamento e não outros. Entre outros fatores, (a) e (b) formam a base para a sua tese das inteligáncias múltiplas. $O$ autor ressalta que cada tipo de inteligência possui suas próprias formas de plasticidade e seus proprios perlodos oritioos (heterocronia).

A versão clássica da teorla computacional da mente passou a ser mais fortemente questionada a partir da década de 70 quando a idéla de processamento simbólico de informaçăo confrontou-se com a idéia de conectividade, entảo resgatada. $O$ conexionismo ${ }^{13}$ formula modelos baseados na analogia neuronal (Rumelhart \& McClelland, 1986). A relaçáo mente-cérebro é tratada através de sistemas de processamento de distribuição paralela, ou seja, ativaçöes elétricas que são descritas como vetores. Permanece a idéla de processamento de infomaçōes (de inputs a outputs) a partir de representaçōes, mas há diferenças substantivas. No mecanismo classico, por exemplo, os objetos aos quais o conteúdo A\&B é ímputado, ou seja, ocorréncias da expressão 'A\&B': literalimente contêm como partes objetos aos quais o conteúdo A é imputado. Além disso, a semāntica, ou as condiçōes de satisfação da expressäo 'A\&B', edeterminada pela semåntica de seus constituintes. No mecarismo conexionista, o conteúdo é imputado ao objeto por uma relação causal (uma relaçäo primitiva), sem uma relação de constituéncia estrutural, do tipo parte-todo. 
Caso se considere a ativação de trés nódulos neurologicamente distribuidos (em que a expressão, 'neurologicamente distribuido' esté ligada à "metáfora do cérebro": as representaçöes "imitam" o funcionamento das redes reuronais) o nódulo (1) A\&B, derivado da ativaçăo dos nódulos (2) A e (3) B, o nódulo (1) afeta causairtrente estados dos nódulos (2) e (3), mas náo é o caso de que (1) e (2) estejam gramaticalmente relacionados a (3). O rotulo A\&B do nódulo (1) indica o seu conteúdo representacional. Esse rótulo tem estrutura, ou seja, tem sintaxe e semântica combinatorial, mas o nódulo a que esse rotulo é atribuido năo tem tal estrutura.

A estrutura constituinte existe quando as partes das entidades semanticamente avaliáveis sấo elas próprias avaliaveis. Um nódulo é neurologicamente distribuido porque, ao que parece, "seus estados de ativaçăo correspondem a padrōes de atividade neural - a grupos de unidades neurais - antes que á ativaçāo de neurônios individuais" (Fodor \& Pylyshyn, t988, p. 20).

McLaughiin (1993) acredita que se deveria tentar implementar a arquitetura clássica no cerebro por uma arquitetura conexionista, de modo que os processos intencionais seriam implementados por processos simbólicos clássicos e estes por processos conexionistas. O autor afimira ainda:

"[O] conexionismo seria mecânica quåntica e o classicisno apenas qulmica. Se houvesse um Prêmio Nobel em psicologia, uma proposta de como uma rede conexionista no cerebro implementa uma arquitetura Gisssica certamente ganharia" (1993, p. 1984).

A argumentaça contra qualquer uma das versठes computacionais da mente simbólica ou conexionista passa por cientistas e filossofos wittgensteinianos, que argumentam que a cogniçăo năo se reduz à manipulação simbolica, opondo-se, portanto, às hipóteses da finguagem do pensamento ou a vertente inatista. Esse é o caso de Button, Coulter, Lee \& Sharrock (1998).

Mas hoje a Teoria de Santiago, cujos expoentes säo Humberto Maturana e Francisco Varela constitui un dos grandes oponentes à idéia de mente como processamento de informaçôes como esta tem sido delineada até aq̣ui ${ }^{14}$

A Teoria de Santiago está inserida no paradigma da complexidade sistemica, baseada na auto-organizaçăo, caracteristica dos sistemes vivos. No caso dos sistemas naturais humanos, conforme Attan (1992), o observador é parte ols a totalidade do sistema. A complexidade é uma orden cujo código nāo conhecemos, afirma Atlan. Isso o que distingue as sistemas humanos de máquinas como a de Turing, cuja estrutura $\mathrm{e}$ funçōes sảo conhecidas, pois se conhece seu projeto de construção e funcionamento. Dos sistemas humanos tern-se, diz Atlan, apenas uma compreensâo imperfeita.

As noçōes de autopoiésis (auto-organizaçāo) e de acoplamento estrutural são centrais para a compreensão do fenómeno mental nesse paradigma e devern ser entendidas a partir de um sistema conceitual que envolve noções mais básicas como: (a) observador: (b) unidades (suscitadas por atos de diștinçăo ou diferenciaçăo de um observador); (c) unidades simples e compostas; (d) organização (relaçoes que se estabelecem entre os componentes de um sistema); (e) estrutura (componentes e relaçóes que constituem uma determinada uniđade); (f) sistemas determinados pela estrutura; (g) existência. Nesse sistema conceitual, desenvolve-se a noçăo de autopoiésis.

Os seres vivos definem-se por sua organizaçăo autopoiética ${ }^{15}$ a qual se caracteriza por um processo em que uma unidade contiruamente se produz a si mesma, à medida que seus componentes estä́o "dinamicamente relacionados numa continua rede de interaçóses" (Maturana e Varela. 1995, p. 85). Em outras palavras, a rede de transformaçoes dinâmicas produz os próprios componentes da unidade.

Uma condiçăo para a organizaçăo autopoiética è a autonomia do sistema, no sentido de que se possa especificar suas leis de constituiçăo. Conforme Atlan (1992), a autopoiésis implica que as regras de organizaçäo sejam internas a sistema, uma vez que este é informacionalmente fechado. Maturana (1996) afirma, hesse sentido, que o que se passa em um ser vivo, a cada instante, está determinado na sua estrutura, nảo em algo externo a ele.

O sistema nervoso em Maturana e Varela e uma rede fechada que se acopla ao organismo que o integra, constiłuindo uma unidade autopolética:

O sistema nervoso, como sistema celutar neuronal, constitui uma rede de elementos interatuantes que se fecha sobre si mesma como uma rede de mudanças de relaços de atividade, tal que toda mudança de relaça de atividade, en uma parte da rede, dá origem a mudanças de relaçóes de alividade en 
outras e na mesna parte da rede. Mas o sistema nerwoso tem uma coisa poculiar: esta acoplado a um organistho (1996, P. 194).

Terr-se um acoplamento estrutural quando a ontogenia (história de mudança estrutura) de uma unidade é acoplada á ontogenia de outra unidade, e suas relaçoes são recorrentes ou estaveis, gerando perturbaçōes reciprocas. $\mathrm{O}$ acoplamento estruturah é, assim, a história de mudanças estruturais recíprocas nà realizaçäo da autopoiésis, gerando a enaçăo: noves configuraçōes estruturais continua e evolutivamente sāo geradas. Utilizando as noçöes básicas, o acoplamento estrutural pode ser definido como:

a relaçă de correspondència dinâmica estrutural com o meio no qual uma unidade consenva sua identidade de classificaça (organjzaçă no caso de una unidade composta, operaçäo de suas proprieda-

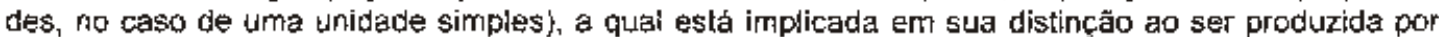
parte do abservador, em sua prática de viver (Maturana, 1996, p. 115)

De um modo amplo, defendese, nessa abordagem, que a base do conhecimento é biológica e tem uma base ontológica no mundo fisico. Todavia, essa não é uma questăo simples. Veja-se o caso da linguagem humana. Para Maturana, embora a linguagem dependa da operaçăo da corporeidade, ela náo term lugar nessa corporeidade. A linguagem tem lugar em dominios de interaçāo social. Um sistena social, por sua vez, é um "sistema no qual os sistema viventes que o compõe se realizam a si mesmos corno sistemas viventes de uma classe particular, atraves de suas coordenaçỏes de aços no dominio de sua aceitaçăo mútua" (1996, p. 71). Conforme Maturana (1996), linguagem e conhecimento näo sāo propriedades inexplicaveis dadas, mas fenômenos do dominio humano de experièncias que surgem na práxis do viver. Na verdade, para ele, nossa condiçęo de existência se encontra na tinguagem, e o dominio físico dessa existência surge na linguagem como um dominio cognitivo.

Nesse cenário epistemológico, a autoconsciência surge da linguagem, e o individuo só existe na linguagem. A linguagem nâo seria meramente um fenomeno do sistema rervoso (neurofisiológico), mas uma relação entre organismos, pois tem hugar no fluir de coordenaçöes comportamentais consensuais desses organismos. A autoconsciência è entendida, fundamentalmente, como fenómeno de autodiferenciaçăo que, como o conhecer, nảo é um fenômeno neurofisiológico, mas "um fenômeno da relaçąa entre um organismo e a circurnstância na qual conserva organizaçāo e adaptaçăo" (p. 201). Ou seja, é um fenômeno social. Diz Maturana que "a realidade surge com a autoconsciēncia na linguagem como explicação da diferenciaçāo entre o eu e o năo-eu na práxis do viver do observador" $(1996, \mathrm{p} .167)$.

A realidade (que Maturana chama de "realidade-entre-parênteses") não existe independentemente do observador, pois surge na linguagem. Cada dominio da existēncia é um dominio da realidade produzido por um observador. Todavia, uma vez produzido um domínio da realidade, o observador pode abordá-lo como se a existência desse dominio fosse independente das operaçōes de diferenciaçäo que o produz. $\mathrm{O}$ "mundo" năo existe independentemente de atos cognitivos. Como afirma Maturana (1996): "cada domínio cognitivo é um dominio de coordenaçōes de açoses na práxis de viver de uma comunidade de observadores" (p. 65)

O ponto fundamentaf é que Maturana e Varala (1995) nāo aderem à metáfora cérebro/mente como um computador, nos termos da arquitetura cognitiva clássica. Para os autores, o sistema nervoso năo è representacionalista,

O sistema nervoso nạo opera com simbolos, opera apenas gerando mudanças de retaçoses do atividade movido por mudanças de relaçōes de atividade. As simbolizaçöes pertencem somente as distinçöes do obseryador, e uma situaça e simbolo de outra apenas em uma distinça que um observador faz (Maturana, 1999. p. 118)

nem dotado de entradas (inputs) e saidas (outputs):

Seria um erro, portanto, definir o sistema nervoso como dotado de entradas a saidas no sentido tradicional [...] ao contrário do que se costuma pensar, o sistema nerroso náo "capta lnformaçóes" do meio, e sim produz um mundo ao especificar que configuraçōes do meio são perturbaçöes e que mudanças estas desencadeiam no organismo (p. 195, grifos da autara).

Os autores negam uma arquitetura mental baseada no processamento de informaçōes, pois, segundo eles, os conceitos de entrada (input) e saida (outpul) se aplicam apenas a sistemas cujas operaçбes implicam o fluxo de matéria, energia ou informaçăo em direçăo ao mejo. Tal fluxo é caracteristica intrinseca de sua constituição. Ao contrảrio desse tipo de sistemas, os seres vivos são sistemas autopoieticos, o que significa que sào sistemas fechados em sua dinämica de estado e só podem existir em autopoiésis. E "sistemas autopoiéticos năo tëm entradas, nem saidas" (p. 260). 
Sfez (1994) sintetiza essa posiçăo dos autores:

Abandonando por interro a representacional e cortwocando a interpretaça en sua ajuda (a realidade exterior não informa o cérebro, o cérebro ngo é uma tela e os neurónios nāo sāo softwares que tratam a informaçăo armazenada), Varela e uma parte dos pesquisadores do seu lime se acham neçessaria e

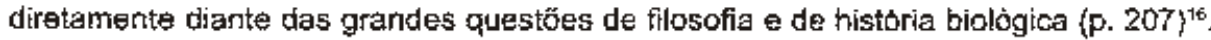

Observe-se, entretanto, que, de acordo com Mothn (1996) - e este é o ponto central deste artigo- devese entender que - a partir da perspectiva da auto-organizaçăo - apesar de os sistemas vivos năo serem assimilàveis às formas dos computadores artificiais - que foram construídos por/programados porioperam para outrem -, todo ser viwo é dotado de uma aparehagem computacional, onde há "computação de si, por si, para si" (p. 318). Esse comportamento é chamado de auto-referente, atito-ecoorganizador:

Uma computaçắ auto-referente é necessariamente eco-referente, isto e, deve ser capaz de trater, examinar, calcular em informaçóes os dados/acontecimentos que coleta no ambiente. Mas a que $\dot{\theta}$ importante è que essa computaçăo trata esses dados como "objetos", precisamente porque o ser computante se constitui comp sujeito, no sentido ent que computa, decide, age de si para si. Portanto, o importante è a afirmaçăo ontológica distinta, única, privilegiada de si para si que caracteriza todo ser vivo (Morin, 1996, p. 318-9).

Maturana (1996) afima, exatamente nesse direçäo, que as máquinas diferem dos sistemas vivos räo pelos principios de funcionamento, mas quanto à referência. No caso da mạ́quina existe alorreferéncia, "a relevăncia de seu funcionamento é determinada pelo modo como satisfaz os desenthos de quem a construiv" (p. 225).

Para os teóficos de Santiago, as caracteristicas peculiares da vida social humana, sobretudo em vista de seu intenso acoplamento lingüistico, geraram a mente e a consciencia". Para eles, no homem, "a linguagem toma a capacidade de reflexão inseparável de sua identidade" (p. 245). Especificamente, dizem:

na rede de interaçós linguisticticas em que nos movernos, mantemos uma continua recursano descritiva que chamamos de "eu", e que nos permite conservar nossa coerenncia operacional lingüistica e rossa adaptaça ao dominio da linguagem (Maturana \& Varela, ig95, p. 251)

Maturana afima que, como seres vivos, acontecemos na linguagem e na linguagem acontecemos como a classe de sistemas vivos que somos, de tal modo que năo há atos de referéncia fora da linguagern. $A$ passagern do social ao biológico baseia-se numa interação em que, apesar de o linguageamento ter lugar no dominio social "como uma dança de relaçōes recursivas de coordenaçôes de ações", as interaçōes:

provocam na existencia fisica dos copos dos participantes mudanças estruturais que alteram as antecedentes fisiológicos (posiçäo emocional), nos quais contiruam expressando-se merdianta a linguagem (Maturana, 1996, p. 150)

O fato é que para Maturana e Varela, ao contrário dos demais filósotos e cientistas da cogniçāo que aderem a alguma das váriess alternativas de aplicaçăo da restriçăo naturalista, o mental näo è algo que estả no erảnio ou um fujdo no cérebro; mental e consciência "pertencern ao domínio do acoplamento social, e neste que se dé sua dinåmica" (1995, p. 252).

As idéas de Maturana \& varela evidenciam que sistemas que se auto-organizam, adaptam-se por aprendizagem nāo-dirigida. E como diz Morin (1996):

A reotganizaçāo permanente $\mathrm{a}$ a autopoese (sic) constituem categonas apliçavejs a toda ordem bjológica e. a fortiori, à ordem sociobógica humana. Uma célula esta em autoproduça permanerte por melo da morte de suas moléculas. Un organismo esta em autoproduça permanente por meio da morte de suas células (qua etc); uma sociedade está en autoproduçáo pemanente por meio da mote de sesus individuos (que gtc); vlas se reporganizam inçessantemente por meio de desordens, antagonisnos, conflitos que thinam sua existencia e, ao mesmo tempo, mantem sua vitalidade (p. 300).

A cultura filosófico-cientifica que define cognição a partir de máquinas digiteis ou conexionistas, cujas operaçōes baseiam-se em processar informaçōes, trouxe grandes contribuiçōes para o estudo do raciocinio no modelo soluçäa-de-problemas; elucidou aspectos dos processos inferenciais demonstrativos, como silogismos e outros raciocinios lógicos; avarçou no tratamențo de inferências nâo-demonstrativas, como as da conversação ordinána: : tambem focalizou-se, como na proposta gardneriana de inteligẽncias multiplas, competèncias construidas e valoradas culturalmente, com amplas conseqüèncias em nivel de programas educacionais, sistemas de aprendizagem $\theta$ avaliaçäo de desempenho no sistema formal de educaçāo. Porém, novos paradigmas, como o da auto-organizaçáplomplexidade, mesmo que ainda fundados sobre alguma noçáo de computo. 
Eontemplam-nos com uma revigorante perspectiva de autonomia, ao mesmo tempo que evidencia novos pepéis para a subjetividade. Ao integrar o observador-sujeito como parte constituinte do conhecimento, um sujeito que hern um lugar cultural e sócio-histórico, bem-se, conforme Morin (1996), uma teoria do sujeito no cerne da ciência, a possibilidade de uma critica do sujeito na e pela epistemologia complexa.

\section{Notas do texto}

'Sobre a "antiga" e a "nova" transdisciplinaridade veja-se Marin (T996).

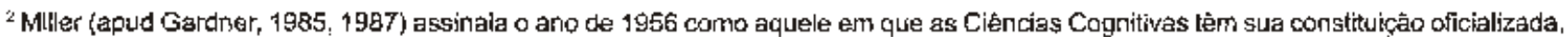
a partil do Symposium on infonotion Theory, realizado no Massachusetts institute of Technology: entre 10 e 12 de setembro daquele ans.

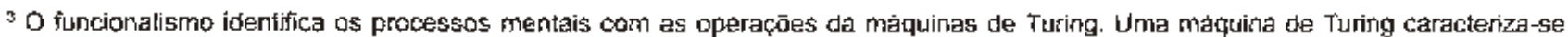

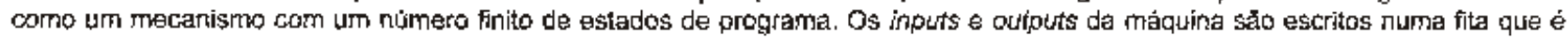

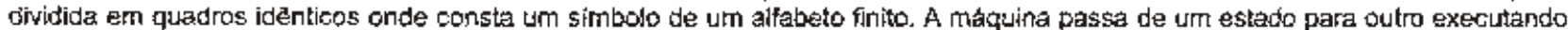

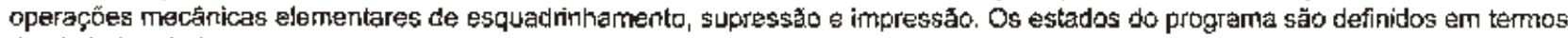

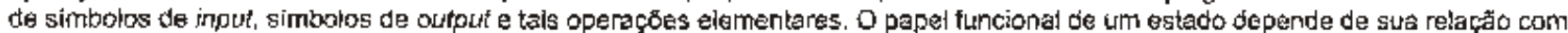

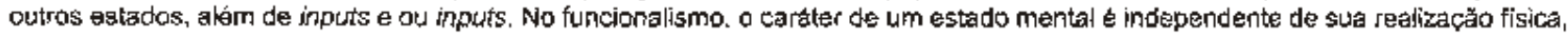

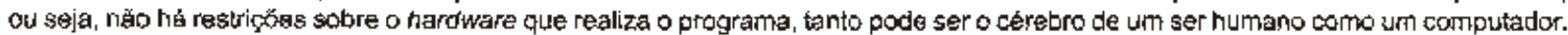
Esse ponto de vigta, era filosofia da mente, remonta a Putnam (1960, 1967a, 1967b, 1975), que sustentz, nessa época, por exemplo, que (a) o ser humano como um todo é Lima máquina de Turing e (b) que selis estados psicohogicos sāo estados dessa máquina. Veja-

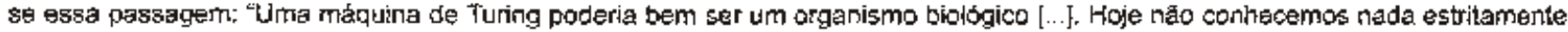

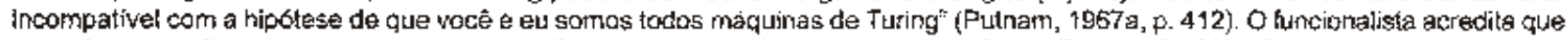

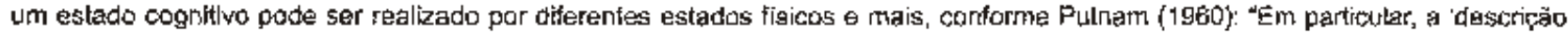

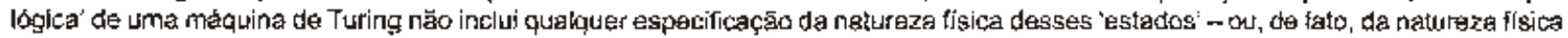

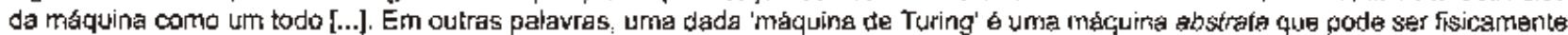

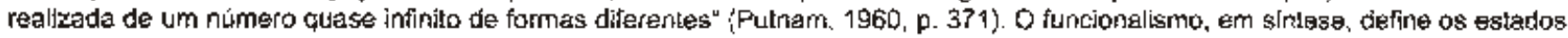

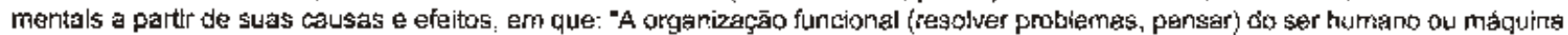

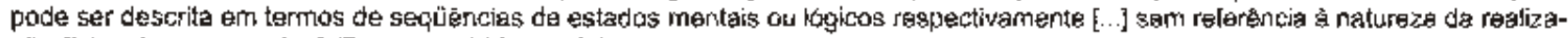
çă fisica desses estados" (Putrath, 1960. p. 373).

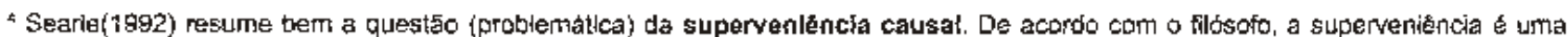

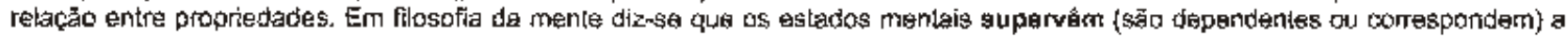

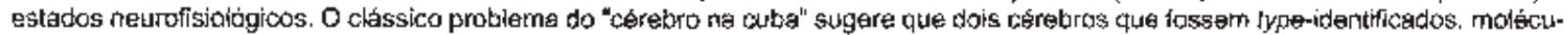

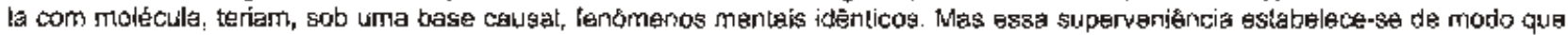

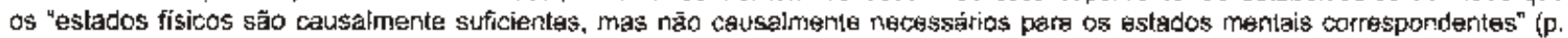

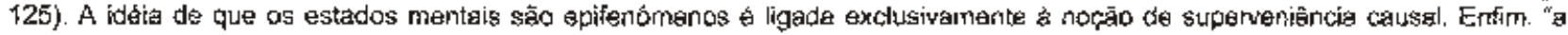

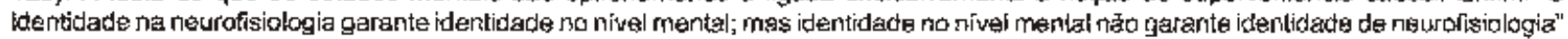
(p. 125).

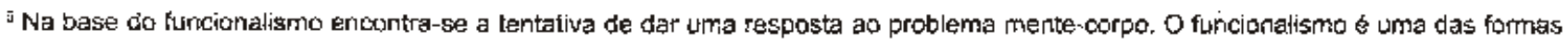

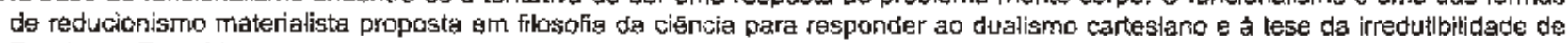

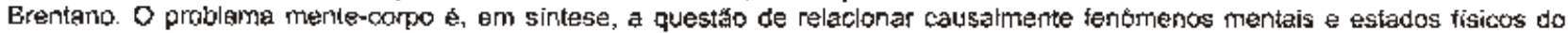
cotpo. A ciência oogrilive enconlra-se angajada em "naturalizar" a mente, atendendo ao que se tem chamado de restrçäo naturalista

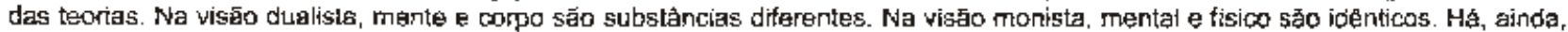

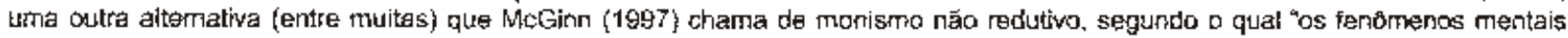

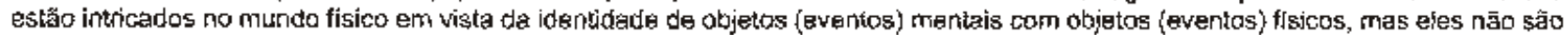

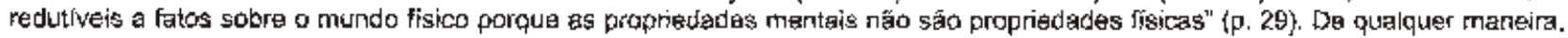

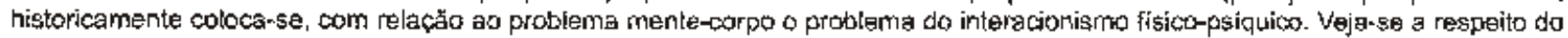
reducionismo Feltes (t9g8a)

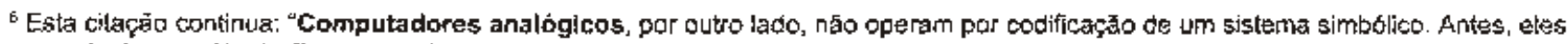

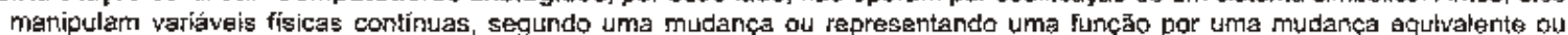

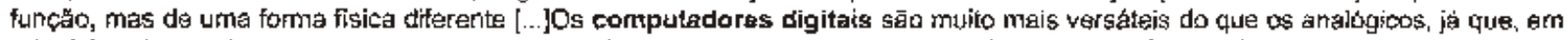

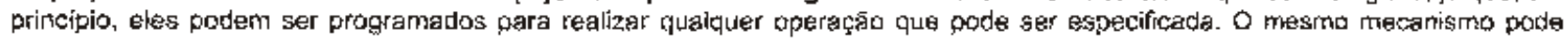

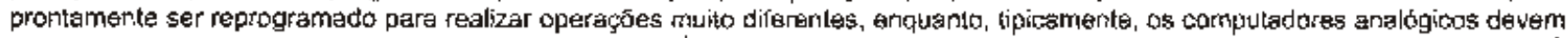

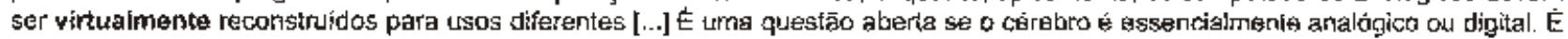
interessante que sejamos extremamente fracos em operaçoses digileis, tais como em problemas arilmelicos complexos, emboric esses

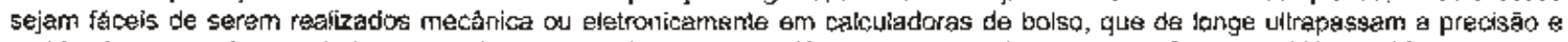
rapldez humanas. Isso pode beri sugerir que o cerebro opere analägica antes que digitalmente" (Gregon, 1987, p. 192-3. Grifos da attoras.

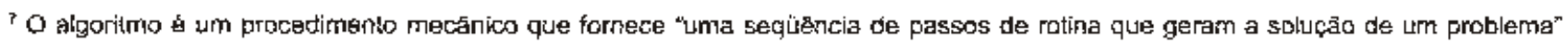
(MoGuKr, 1996, p. 109).

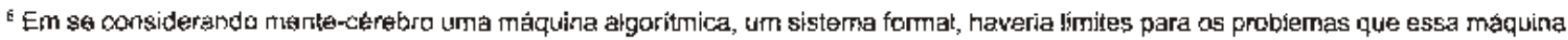

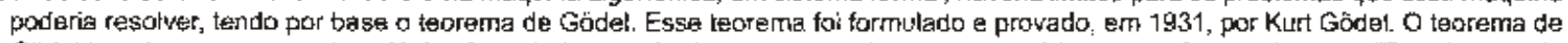

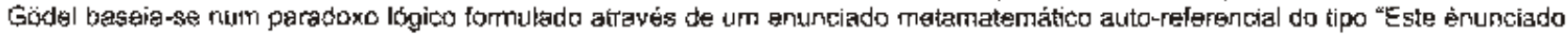

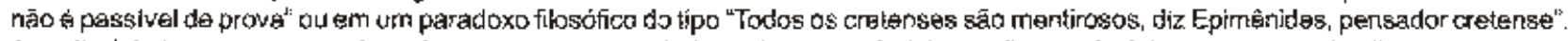

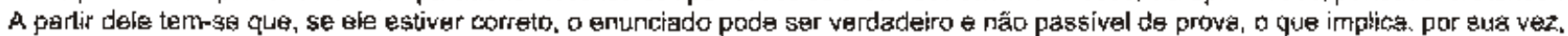

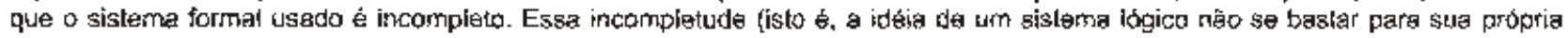

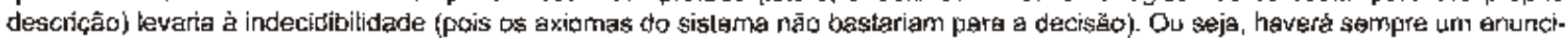

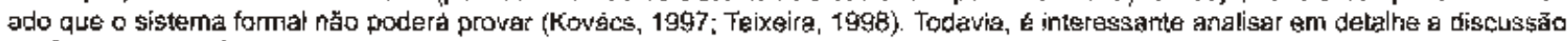
de Chamgevux Confues em Changeaux 2 Connes (1996j sobrs objeçoss a aplicaça do teorema da incompletude a determinados desenvolwistantos da neuraciéncia. 
"Segundo Dennett \& Haugeland (in Gregory, 1987), b temo 'ittencionalidade' foi cunhado pelos escolásticos na ldade Mèdia e foi revivido no século XJX pelo psicologo Franz Brentano, predecessor da escola fenomenolódica. Para Brentans, a jntencionalidade e que distingue o mertal do ffsico: todos e apentas os estados mentais exibem intencionatidade. Desde que a intencioralidade e traço

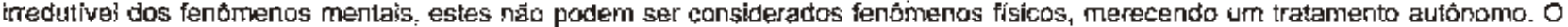
que se tem chamado de o Problema de Brentano é a tentativa de dar uma abordagem nafuralista da intencionalidade. Dada a posiçäo cept|ca de Brentano, a Problema tamberm bonhecido como a Tese da irredulibilidade. Ainda segundo os autores, nas dècadas de 60 e 70, o temo 'intenctonalibada' é revivido gor fildsofos ingleses e americaros da tradiça analítica, bamo chishotm e Ouine, e abordada en lempos logicos e semanticos.

te $O$ solipsismo, em iermas genericos, a a tese de que possa haver ung linguagem cujos significados advem apenas dos contevidos da

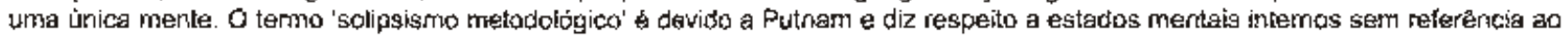
mundo extemo. Em Ciencia Cogniliva, a lermo 'solipsismo' \& tomado de diferentes formas. Segundo Trajger (1991), há prelo trék: versōes do solipsismo: (a) o solipsismo ontológico que advoga a primazia da consciendia introspectwa: (b) a solipsismo epistemołógies, a partir do qual as unicas coișas de que se prode tomar conhecinento săo os proprios astados (do próprio indivitulo com relaçäo a si mesmo); e (c) o solspsismo metodológica, a partir do qual "o que é relevanle para entendar a mente a a represen-

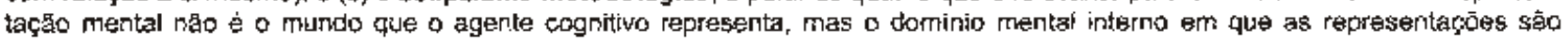
construldas" (Traiger, 1991, p. 2)

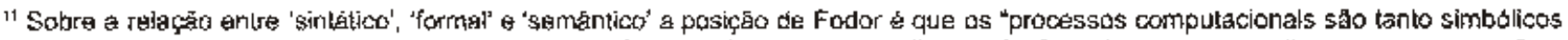

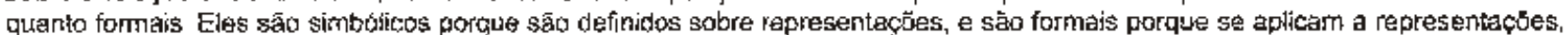
emr wista (a grosso modo) da sintaxe das representaseses [...] Dizer que urfa operaçäo é formal näo é o mesmo que dzer que

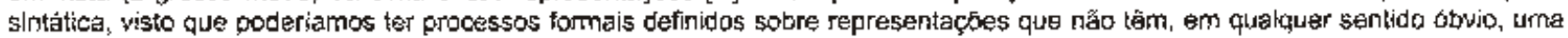

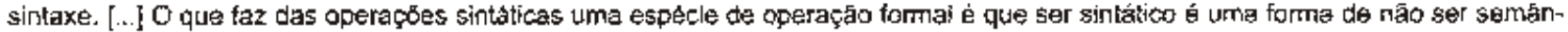
tico" (1981, p. 226-7).

12 A apresentaçầ da hipotese de modukaridade da mente aqui apresentada f uma adaplaçò de exposiços mais detalhadas feltas em Feltes (1995) 8 Silveira e Feltes (1998).

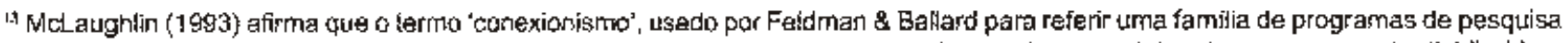
em ciancia cogritiva, passou a ser usado para cobrir lodos de programas que desenvolverth modelos de processamento distribudo e

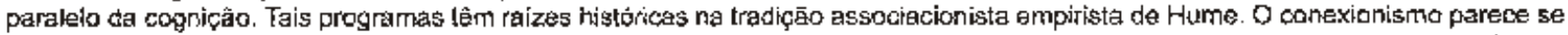

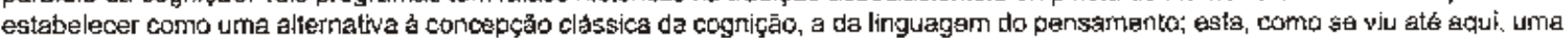
concepco computacional da riente baseada na tharioulaga de stribolos gowemados por regras - uma tmetélora do computador

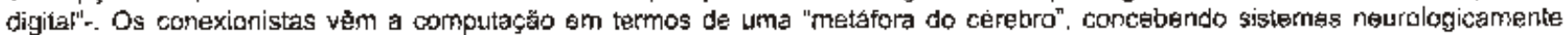

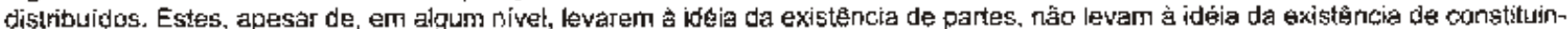
tes. No presente lexto, a caracterizaçäo do conexionismo é bastante deficttária em vista do espaço lifrilado a complexidade téchica dà descriç̧o envolidida.

14 A. Teria de Sartiago desenwolve-se ao longo da decada de 70. Sfaz (1994) chlegoriza-a cotro um "pos-neoconexionismo" (p. 207)

12 Mesmo dejxando de ladp aqui o tratanento de todo o framework conceitual das foorias sistemicas, flndadas na idéria de padräo de organlzaço e de auto-ornanizaçăg, e que săo o quadro referencial da abondfgem da Escola chilena, é importante mencionar que

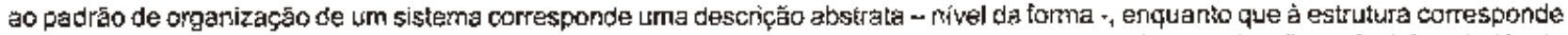

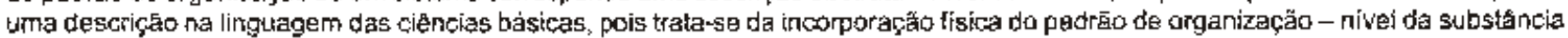

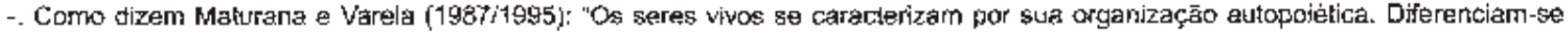
entre si por teren estruturas diferentes, mas sä́ iguais em sua orgenizaçä" ( $\rho .37)$

19 Na vertade, Sfez (1996) deserwolve uma longa critica, woltando-se mais para aigurmas obras e entrevistas de varela, tanto que eo

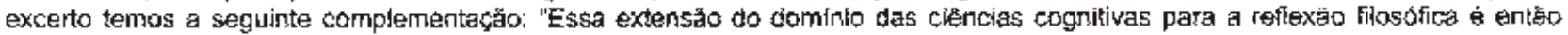

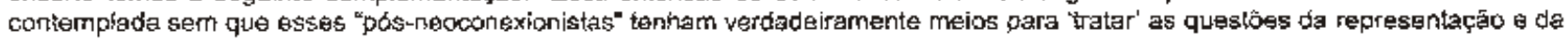

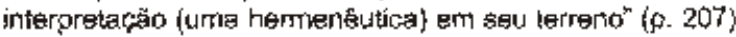

1" Maturana cuntha a expressáo, "lenguajear" (no portuguess, "Finguageamento") para referir-se ao fato de que "expressar-se pela linguagem en interatuar estruturalmente $e^{n}$ (p. 150 )

14. Veja-se, por examplo, o modelo ostengivo-jiferencial de comanicaça, de Dan Sperber e Deirdre Wilson apresentado em Silweira e Felles (tog9).

\section{Referèncias bibliográficas}

ATLAN, Herri. Entre o cristal e a furnaçą ensaio sobre a organizaçăo do ser vivo. Rio de Janeiro: Zahar, 1992.

FELTES, Heloisa Pedroso de Moraes. A arquitetura modular da mente na teoria da Relevancia e nas semanticas cognitivas, Cadernos de Pesquisa, w. 4, n. 6. p.157-206, now. 1996.

Naturalizaçāo da semântica das representaçōes mentais. Teşe dẹ Doutoramento apresentada junto ao PósGraduaçăo em Letras da Pontificia Universidade Catblica do Rio Grande do Sul, $1998 \mathrm{.}$

Relacōes intramodulares e intermodulares: a interface sintaxe-semanntica e stafus dos papéis temáticos. Coletânea Cultura e Saber. Vol. 2, r. 1, set. 1998b.

FODOR, Jerry A. The language of thaught. Hassocks, Sussex: The Hawester Press, 1976.

Representations; philospphical essays on the foundations of cognitive science. Cambridge, Mass.: A Bradford Bopk The MIT Press, 1981.

The modularity of mind; an essay on facutty psychology. Cambridge, Mass.: A Eradford BookThe MtIT Press, 1983.

Psychosemantics; the problem of meaning in the philosophy of mind. Cambridge, Mass.: A Bradford Book/ 
The Mit Press, 1987.

A theory of content and other essays. Cambridge. Mass.: A Bradford BookThe MIT Press, 1990.

FODOR, Jerry A. and PYLYSHYW, Zenon. Comnectionsm and cognitiwe architecture; a critical analysis. Cognition, $v, 28, p$. $3-7 \uparrow, 1988$.

GARDNER, Howard. Frames of mind: the theory of multiple intelligences. New York: Basic Books, 1983 \{Tradução para a lingua portuguesa de Sandra Gosta: Estruturas da mente: a teria das inteligencias múltjpias. Porto Alegre: Artes Médicas, 1994.$]$

The mind's new science: a history of the cognitive revolution. New York: Basic Books, 1985. fA edicăo de 1987, en paperback, conta com o epilogo: Cogrifive Sclence after $1924 \mathrm{~A}$

GREGORY, Richard $\mathrm{L}$. The Oxtord companion to the mind. New York: Oxford University Press, 1987.

JACKENDOFF, Ray. Semantics and cognition. Cambridge. Mass.: A Bradford Bodks/The MtT Press, 1983.

Consciousness and the computational mind. Cambridge. Mass.: A Bradford Book, 1987

Languages of the mind; essays on mental representation. Cambridge, Mass.: A Bradford Bogk The MilT Press, 1992.

KOVACS, Zsolt L. O cérebro e sua mente; uma introduçáo à neurociéncja computacional. Sáo Paulo: Edição Académica, 1997.

LEVY, Piere. La machine univers: création, cognition et culture informatique. La Découverte: Paris, 1967.

As teçnologitas da inteligéncia: o futuro do pensamento na era da informática. São Paulo: Editora 34,1993

MATURAMA, Hunberto La realidad: objetiva o construjda? H. Fundamentos biológicos del conocimiento. Barcelona: Anthropos; Mexico: Universidad Iberoamericna; Guadalajara; Instituto Tecnologico y de ostudios Superiores de Occidente, 1996

A ontologia da realidade. Belo Horizonte: Ed. UFMG, 1999. (orgs. Cristina Magro; Mirian Graciano; Nelson Vaz)

MATURANA, HUmberto e VARELA, Francisco G. A arvore do conhecimento; as bases biológicas do entendimento humano. Campinas: Editorial Psy, 1995.

MCGINN, Colin. The character of mind; na introduction to the philosophy of mind. 2.ed. New York; Oxford Uniwersily Press, 1997.

MoLAUGHLIN, Brian P. The conectionismiclassicism batte to win souss. Philosophical Studies, $w .71, n .2, p .163-190$, aug. 1993

MORN, Edgar. Ciencia com consciòncia. Rio de Janeiro: Bertrand Brasil, 1996.

POPPER, KarF R. e ECCLES, John C. O eu e seu cerebro. Campinas: Papirs; Brasilia: Ed. LnB, 1991.

PUTNAM, Hilary. Minds and machines In: - . Mind, Language and Reality. Cambridge: Carnbridge University Press, (1960) 1975, , $362-407$.

The mental life of some machines. h: --. Mind, Language and Reality. Cambridge: Cambridge University Press. (1967a) 1975 , p. $408-28$

The nature of mental states. In: - Mind, Language and Reality. Canbridge: Carnbridge Universily Press, (1967b) 1975, . . $429-40$.

Philosophy and our mental life. lin: - Mind, Language and Reality. Cambridge: Cambridge University Press, (1973) 1975, p. 291-303.

. The meaning of 'meaning'. In: -... Mind, Language and Reality. Cambridge: Cambridge University Press, $1975, p$. 215-71.

PYLYSHYN, Zenon W. Computation and cognition: toward a toundation for eognitive science. Cambridge, Mass.: MIT Press, 1986.

RUMELFART, D. E. $\rightarrow$ MCCLELLAND, J. L. Parallel distribuid processing: explorations in the microestruture of cognition. Cambridge, Mass: The MiT Press, J986. Foundations I.

SFEZ, Lucien. Critica da comunicaçāo. Sāo Pauto: Edtçōes Loyola, 1990. Tradução de Maria Stela Gonçalves e Adail Ubirajara Sobral.]

SHVEIRA, Jane Rita Caetano da. e FELTES, Heloisa Pedroso de Moraes. Pragrtática e cogniçäo: a textualidade pela Relevärcia. 2. ed. Porto AlegrelCaxias do Sul: EDIPUCRSJEDUCS. 1999

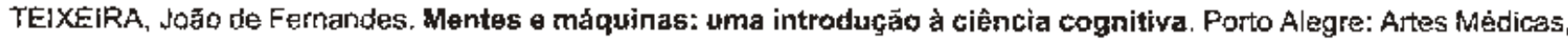
1998.

TRAFGER, Saut. Solipsism, individualtsm and cognitive science. Journal of Experimental and Theoretical Artificial Intelligence. vol. 3, p. 163-70, 1991 [Ototido na initernet: sics. fitmlat www oxy edu., p. 1-8.] 